\title{
The pleasure of food: underlying brain mechanisms of eating and other pleasures
}

\author{
Morten L Kringelbach ${ }^{1,2}$
}

\begin{abstract}
As all chefs know, great food can have a transformational impact. A great deal of recent research has gone into using the new techniques from molecular gastronomy and gastrophysics to create innovative meals with delicious original textures and flavours. These novel creations have elicited much excitement from food critiques and diners alike. Much stands to be gained if these developments were to be matched by a better understanding of how the pleasure of food comes about in the brain. This review summarises the current state-of-the-art of the science of pleasure and specifically the brain's fundamental computational principles for eating and the pleasures evoked. It is shown how the study of food has advanced our understanding of the unitary pleasure system that is used for all pleasures. As such, these novel insights may come to serve as a guide for chefs of how to combine science and art in order to maximise pleasure - and perhaps even increase happiness.
\end{abstract}

Keywords: Dinner, Gastronomy, Brain, Pleasure cycle, Satiety, Satiation, Hedonic, Pleasure, Food, Multimodal integration, Insula, Operculum, Orbitofrontal cortex, Cingulate cortex, Wanting, Liking, Learning, Anhedonia

\section{Introduction}

The novella "Babette's Feast" by the Danish writer Karen Blixen (writing under her nom du plume of Isak Dinesen) is set in the 1870 s, describing an austere religious sect, whose members "...renounced the pleasures of this world, for the earth and all that it held to them was but a kind of illusion, and the true reality was the New Jerusalem toward which they were longing" [1]. Martine and Phillipa are the unmarried daughters of the founder of the religious sect who have a French maid-of-all-work, Babette, appearing from war-torn Paris under mysterious circumstances. Upon her arrival, the pious daughters are anxious to avoid any "... French luxury and extravagance" and therefore at the time explained that they "... were poor and that to them luxurious fare was sinful. Their own food must be as plain as possible". As it happens, their worries are allayed; and for next 12 years, Babette serves them such that the whole community come to acknowledge her excellence and depend on her quiet gifts. When Babette unexpectedly wins a princely sum of money in the French lottery, they become afraid she may leave

Correspondence: Morten.Kringelbach@psych.ox.ac.uk

${ }^{1}$ Department of Psychiatry, University of Oxford, Warneford Hospital, Oxford OX3 7JX, England

${ }^{2}$ Center of Functionally Integrative Neuroscience, Aarhus University, Aarhus, Denmark

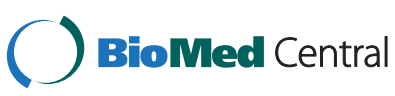

them. Accordingly, against their better judgement, the sisters agree that Babette may cook them a special dinner celebrating the 100th anniversary of the sect's founding father. Unbeknownst to the sisters, Babette used to be a cordon bleu cook who prepares a sumptuous once-in-alifetime meal, leaving the guests questioning their lifelong denial of mortal pleasures.

In the novella, this cathartic meal is not described in much detail, following the vow of the devout and taciturn guests "... not to utter a word about the subject". In contrast, Danish director Gabriel Axel's Oscar-winning film adaptation tries hard to use visuals to convey the splendour of the dinner but still falls short of conveying the multisensory experience of a fine meal. Blixen is astute in using linguistic sparseness as a plot device, given that language, even that employed by great writers [2], very often fails to convey the exquisite sensory experiences of food upon which the story hinges. Blixen even feels moved to suggest that it is "... when man has not only altogether forgotten but has firmly renounced all ideas of food and drink that he eats and drinks in the right spirit". Language for all its powers is powerless when it comes to evoking the food's sensory routes to pleasure, yet the unity of pleasure is beautifully evoked: "Of what happened later in the evening nothing definite 
can here be stated. None of the guests later on had any clear remembrance of it. They only knew that the rooms had been filled with a heavenly light as if a number of small halos had blended into one glorious radiance. Taciturn old people received the gift of tongues; ears that for years had been almost deaf were opened to it. Time itself had merged into eternity. Long after midnight the windows of the house shone like gold, and golden song flowed out into the winter air".

Thus, Babette's feast becomes a route to intense wellbeing, and the pleasure is not just about the food but instead about providing unity and transcendence for the virtuous dinner guests who all leave the meal changed, suddenly awake to the potential of earthly pleasures.

For many years, such pleasures have remained mysterious and firmly within the domain of much great art. Yet, the advent of modern neuroscience has started to uncover some of the underlying mechanisms of associated brain changes.

This review describes what is known of the processing of food in scientific terms; from sensory identification of the uni- and multisensory properties of food to the associated prediction, memory and evaluation involved which may give rise to the experience of pleasure. Like all rewards, food depends on processing in interconnected and widespread brain regions to identify and characterise the different sensory properties and their multimodal integration. This processing is detailed in a multilevel model of the constituent processes involved in food intake over time. The focus here, however, is on the fundamental underlying brain mechanisms governing the initiation and termination of a meal leading to pleasure. Overall, the accumulated evidence shows that the pleasure evoked by food is remarkably similar to that of other rewards, suggesting a unitary pleasure system, whether engaging with food, sex, social or higher-order rewards. Food is thus not only highly pleasurable but also an excellent tool for discovering fundamental principles of brain function.

\section{Brain principles of eating}

While food clearly is essential to survival, it is the pleasure involved that makes eating worthwhile. While the members of the religious sect in Blixen's novella may try hard to deny the pursuit of pleasure in its many forms, their well-being is ultimately strongly enhanced as they submit to Babette's cooking, i.e. to the strong primal drive for pleasure. The evolutionary imperatives of survival and procreation are not possible without the principle of pleasure for the fundamental rewards of food, sex and conspecifics-and as such may well be evolution's boldest trick [3]. The scientific study of pleasure, hedonia research, is dedicated to searching for the functional neuroanatomy of hedonic processing, taking its name from the ancient Greek for pleasure ( $\dot{\eta} \delta o v \dot{\eta}$;

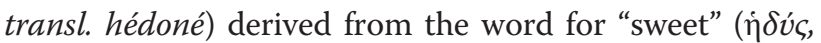
transl. hèdús) [4].

In the novella, the sect's initial food asceticism may stem from their religious beliefs but is guided by the basic homeostatic regulation of human eating behaviour [5], of which animal models have elucidated in great details the many subcortical circuits and molecules shared amongst mammals including humans [6-8]. Yet, as illustrated by the effects of Babette's Feast, homeostatic processes are not solely responsible for human eating. This hedonic eating is difficult to suppress and is even more poignantly illustrated by the current worldwide obesity pandemic [9]. There is often very little well-being linked to such over-eating, with anhedonia-the lack of pleasure-being a prominent feature of affective disorders. From this public health perspective, it is imperative that we better understand the fundamental pleasure systems such that we find new and more effective ways of rebalancing the system and potentially reducing obesity which is threatening to undermine public health [10].

Eating can seem simple but at its most basic, human food intake is still rather complex. The procurement of food can be surprisingly difficult in the wide variety of often hostile climates inhabited by humans. Once food is available, the preparation and eating of food are also complex processes, involving a multitude of peripheral and central processes for carefully orchestrated acts requiring significant brain processing. The necessary, sophisticated motivational, emotional and cognitive processing are likely to have been main drivers for the evolution of large primate brains [11]. The brain principles underlying eating have been investigated for a long time in many mammalian species $[6,12]$. Here, the focus is on the pleasure component of human eating, which over the last decade has started to transform our understanding $[13,14]$.

To understand pleasure in the brain, it is important to consider the main challenge for the brain which is to successfully balance resource allocation for survival and procreation [15]. In order to achieve this balance, different rewards compete for resources over time. In understanding the multi-faceted nature of pleasure, it can therefore be useful to consider the typical cyclical time course shared between all rewards with distinct appetitive, consummation and satiety phases [16,17] (Figure 1). The research has demonstrated that pleasure consists of multiple brain networks and processes and involves a composite of several components: "liking" (the core reactions to hedonic impact), "wanting" (motivational processing of incentive salience) and learning (typically Pavlovian or instrumental associations and cognitive representations) [18-21]. These component processes have discriminable neural mechanisms, which wax and wane during the cycle. The neural mechanisms of wanting, liking and learning can occur at any time during the 


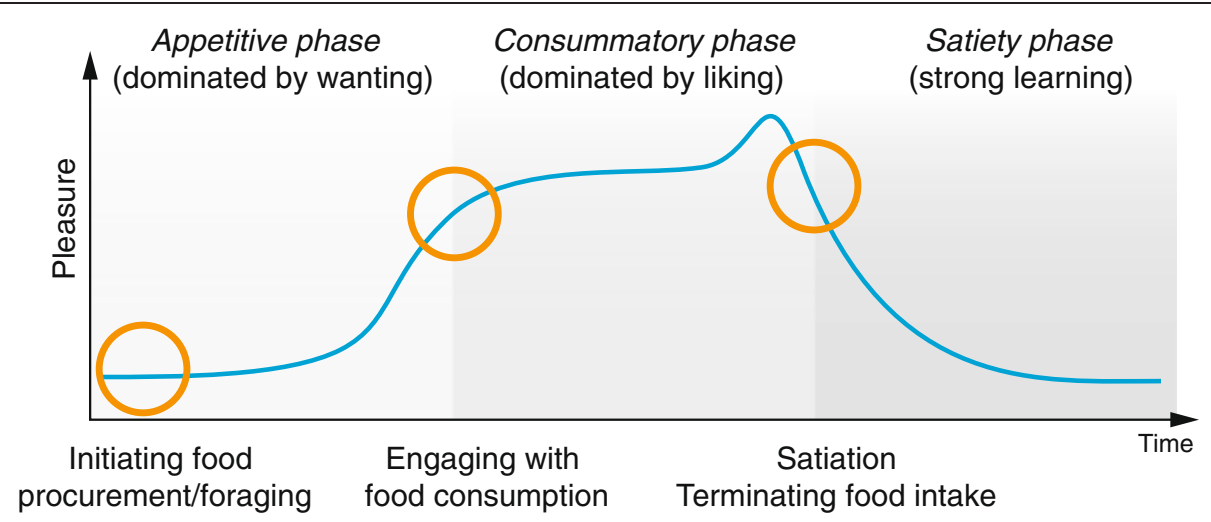

Figure 1 The pleasure cycle. The cyclical processing of rewards has classically been proposed to be associated with appetitive, consummatory and satiety phases $[16,17]$. Research has demonstrated that this processing is supported by multiple brain networks and processes, which crucially involves liking (the core reactions to hedonic impact), wanting (motivational processing of incentive salience) and learning (typically Pavlovian or instrumental associations and cognitive representations) [18-21]. These components wax and wane during the pleasure cycle and can co-occur at any time. Importantly, however, wanting processing tends to dominate the appetitive phase, while liking processing dominates the consummatory phase. In contrast, learning can happen throughout the cycle.

pleasure cycle, though wanting processes tend to dominate the appetitive phase (and are primarily associated with the neurotransmitter dopamine), while liking processes dominate the consummatory phase (and are associated with opioids) [13]. In contrast, learning can happen throughout the cycle (and is thought to be associated with synaptic plasticity). A neuroscience of pleasure seeks to map the necessary and sufficient pleasure networks allowing potentially sparse brain resources to be allocated for survival.

This basic cyclical model of pleasure can be expanded into an elaborate multilevel model of food intake taken in account the episodic and tonic changes over time (Figure 2) [12]. The model links the pleasure cycle with the cyclical changes in hunger levels related to the initiation and termination of meals and the way food intake

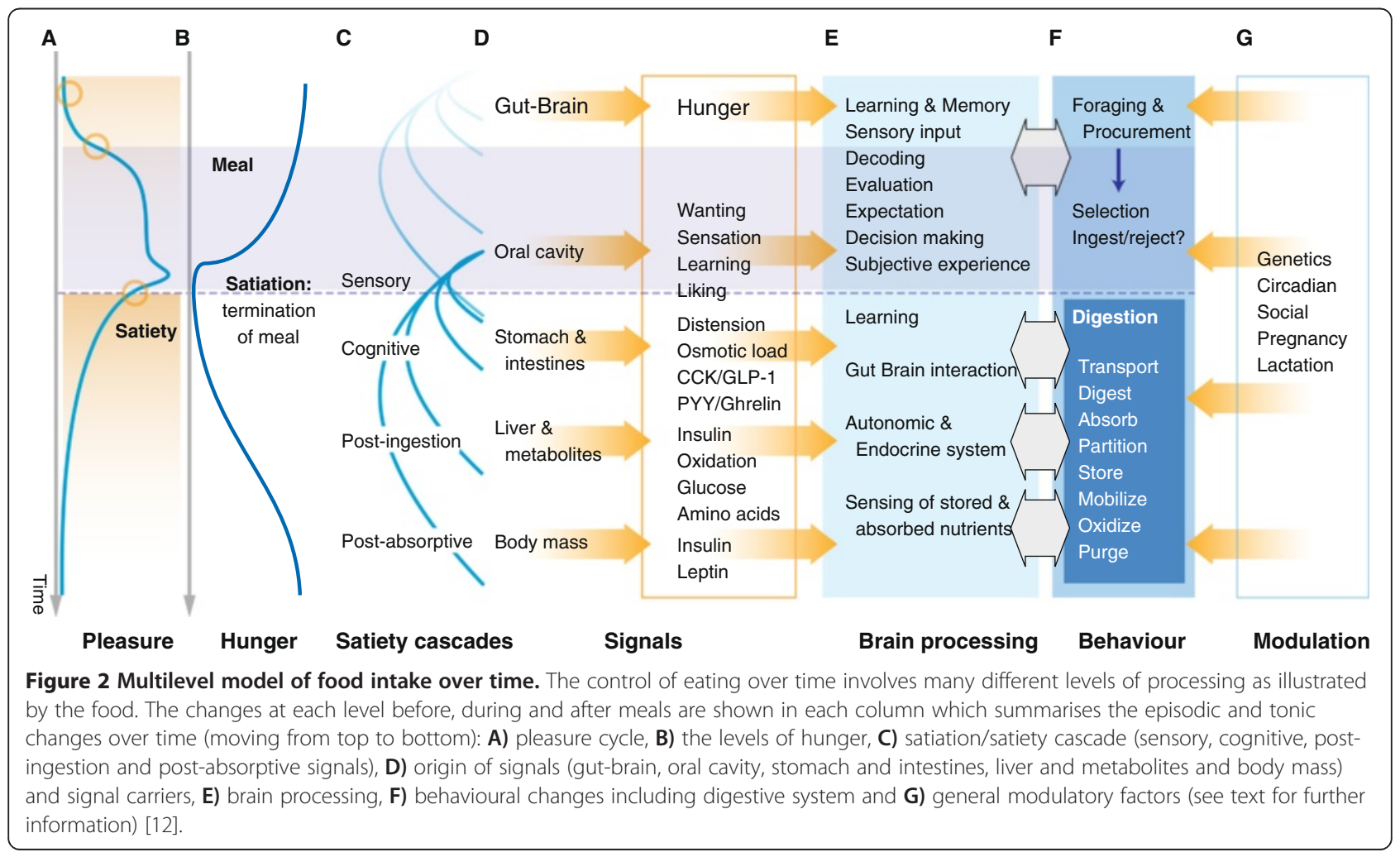


comes about through the interaction given signals from the body, e.g. from the brain, gut-brain, oral cavity, stomach and intestines, liver and metabolites and body mass.

The dual processes of satiation and satiety are central to the model and to the energy obtained by the associated meals [22]. Terminating eating is complex process, which is encapsulated by satiation [23], while satiety is the feeling of fullness that persists after eating to suppress further eating. These processes are controlled by a cascade of sensory, cognitive, post-ingestion and post-absorptive signals, beginning with the consumption of a food in a meal and continuing as the food is digested and absorbed.

The multilevel model of food intake describes the changes over time in A) pleasure, B) the levels of hunger, C) satiation/satiety cascade signals, D) origin of signals and signal carriers, E) brain processes, F) behavioural changes including those in the digestive system and G) general modulatory factors (Figure 2). Many of these changes have been described elsewhere, e.g. the mechanisms of the changes after the termination of a meal such as the gut- brain interactions, include signals from receptors in the digestive tract which are sensitive to calorie-rich nutrients (even in the absence of taste receptors) [24,25].

Here, however, the focus is on the processing principles involved primarily in the initiation and termination of a meal (Figure 3). The multisensory experience of food intake involves all the senses with different routes into the brain; from the distant processing of sight, sound and tactile of food to more proximal smell, taste and tactile (mouth-feel) processing. Smell is the most important determinant of the flavour of food and comes to the brain via orthonasal and retronasal pathways, experienced as we breathe in and out, respectively [26]. As demonstrated by the case with coffee, the subjective olfactory experience can feel very different from smelling the coffee in the cup to tasting the coffee in the mouth, which also relies on pure tastants (such as bitter) and mouth feel factors (such as the smoothness of the crema) (Figure 3A).

This sensory information about food is coming from receptors in the body, typically the eyes, ears, nose and

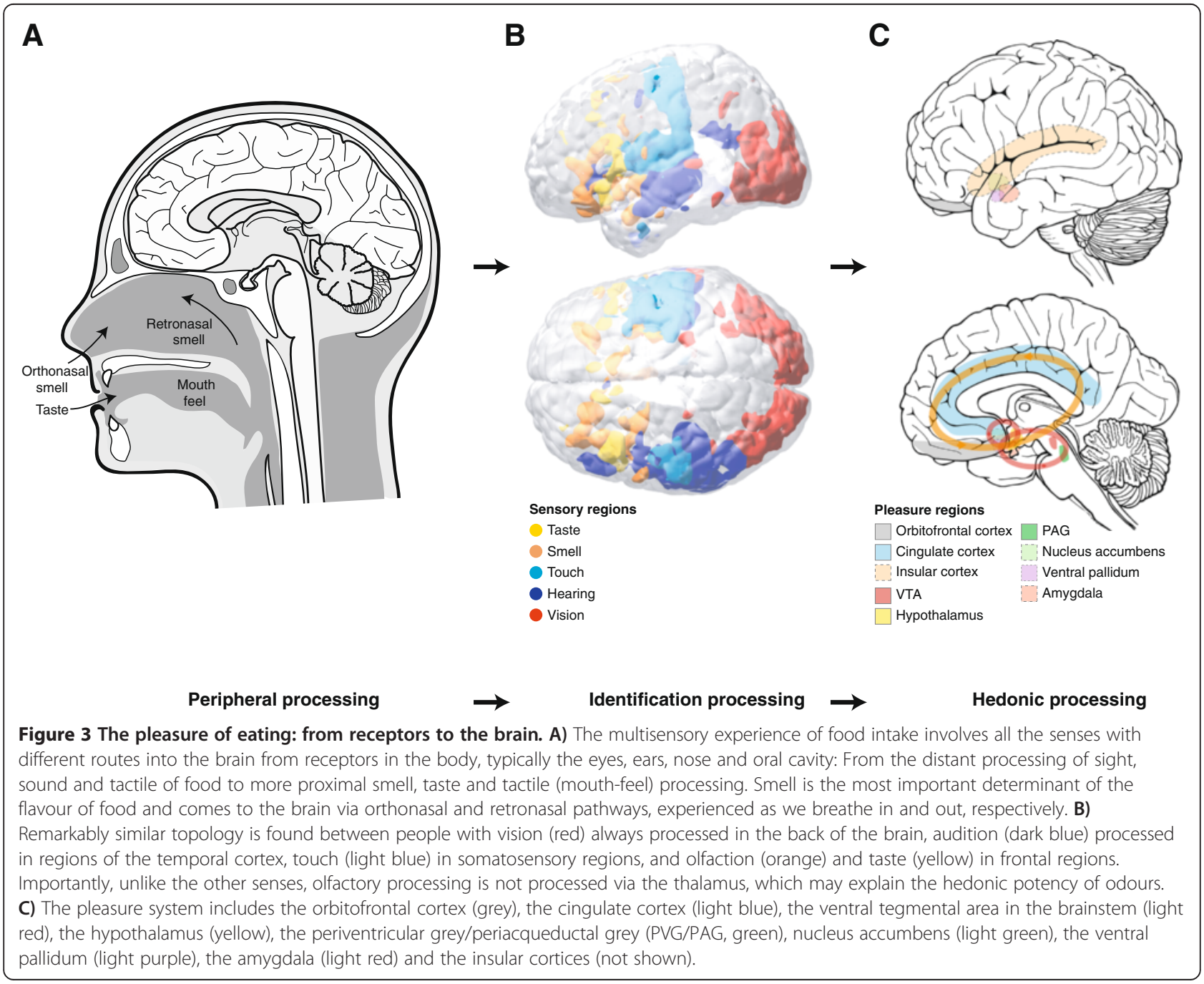


oral cavity and gets processed in the primary sensory cortices of the brain. The topology of these regions are remarkably similar between people with vision (red) always processed in the back of the brain, audition (dark blue) processed in regions of the temporal cortex, touch (light blue) in somatosensory regions and olfaction (orange) and taste (yellow) in frontal regions (Figure 3B). Importantly, unlike the other senses, olfactory processing is not processed via the thalamus which may explain the hedonic potency of odours [27]. Note that it is important that we are able to identify a food stimulus independently of whether we are hungry or sated, and accordingly, sensory information in primary sensory cortices is remarkably stable and not modulated by motivational state.

The sensory information is further integrated in multisensory areas before it is evaluated for reward value in the pleasure system. Here, the processing depends on prior memories, expectations and state and may give rise to brain activity which gives rise involuntary pleasureevoked behaviour (such as licking of lips or soft moaning) and, at least in humans, subjective pleasure (Figure 3C).

Neuroscience has started to map the pleasure system in many species. This has been shown to include a number of important regions such as pleasure hotspot regions in subcortical areas of the brain such as the nucleus accumbens and ventral pallidum $[28,29]$. Manipulations of these regions with opioids have been shown to causally change pleasure-elicited reactions [13]. Other regions involved in pleasure have been found using human neuroimaging in the orbitofrontal, cingulate, medial prefrontal and insular cortices [30-37]. The pleasure system does not act in splendid isolation but is of course embedded within much larger brain networks. We are beginning to understand the metastable nature as well as the topological and functional features of these networks using advances in network science and graph theory together with advanced whole-brain computational models [38,39].

\section{Computational processing principles for eating}

Overall, eating has been demonstrated to rely on at least five fundamental processing principles: 1) hunger and attentional processing; 2) motivation-independent discriminative processing of identity and intensity; 3 ) learning-dependent multisensory representations; 4) reward representations of valence and 5) representations of hedonic experience $[12,40]$. In the following, these are briefly described.

\section{Hunger and other attentional processing}

Typically, changes in ongoing brain activity are driven by changes in the internal or external environment, signalling that the brain needs to start to reallocate resources and change behaviour. This motivational drive for change is strong for food intake, where hunger is a major attentional signal that along with other homeostatic signalling can influence the brain to initiate food-seeking behaviours, typically following the satiety phase from the previous meal. The hunger information comes primarily from gutbrain interactions signalling if the nutrients eaten in the previous meal have yielded the expected amount of energy but a large part is also played by habit (such as regular meal times) and learning, including social interactions which may lead to overeating due to diminished attention towards the food [41,42]. Signals from receptors in the gut and in the circulatory system are vital in initiating eating through conveying messages for the need of nutrients or energy uptake [6,43].

The healthy system is balanced through careful monitoring and learning throughout life. In the presence of sufficient nutrients, healthy adults are able to maintain a stable body weight by careful management of nutrient uptake, energy needs and the balance with energy expenditure [44]. In animal models, this homeostatic component has been shown to relate to activity in hypothalamic circuits including the arcuate nucleus [6,43]. Hedonic influences beyond homeostasis can lead to malfunction to this control of energy balance, e.g. leading to obesity, potentially through a mismatch between the expected pleasure compared to the actual energy uptake from food intake $[11,45]$.

\section{Motivation-independent processing of identity and intensity} It is vital that reliable sensory food information is provided for the brain to guide ingestion decision-making. Eating has to be controlled very carefully since erroneous evaluation of the sensory properties of foods can potentially be fatal if ingesting toxins, microorganisms or non-food objects. Mammals have been shown to have brainstem reflexes (stereotypical for each basic taste) that are based on rudimentary analyses of the chemical composition, and which are not altered, even by the loss of all neural tissue above the level of the midbrain [46]. Eating-related behaviours in humans and other animals can usefully be described as a strategy to maintain a balance between conservative risk-minimising and lifepreserving strategies (exploitation) with occasional novelty seeking (exploration) in the hope of discovering new, valuable sources of nutrients [47].

The sensory information about the identity and intensity of a food-sometimes called a flavour object-reaching the primary sensory cortices appears to be motivationindependent [48]. This principle has been demonstrated by neurophysiological and neuroimaging experiments using five basic pure tastes of salt, bitter, sour, sweet and umami to locate the primary taste area in humans in the bilateral anterior insula/frontal operculum [49-53] (Figure 4). Please note that one study has reported changes in activity in the primary taste cortex by expectancy [54]; but unfortunately, the authors did not publish the 


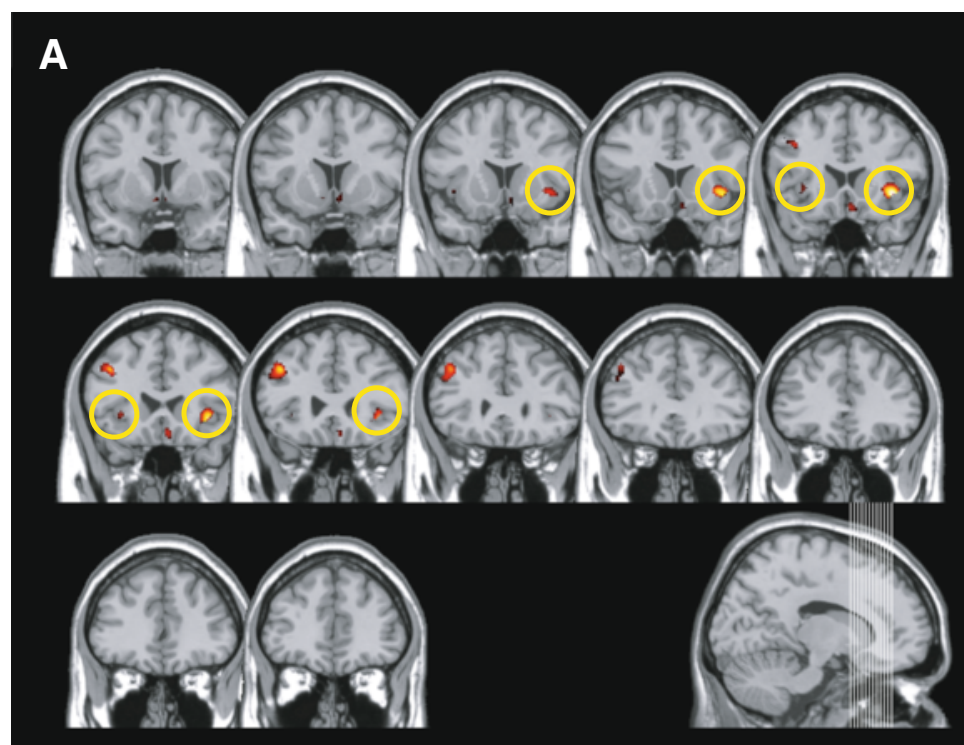

B
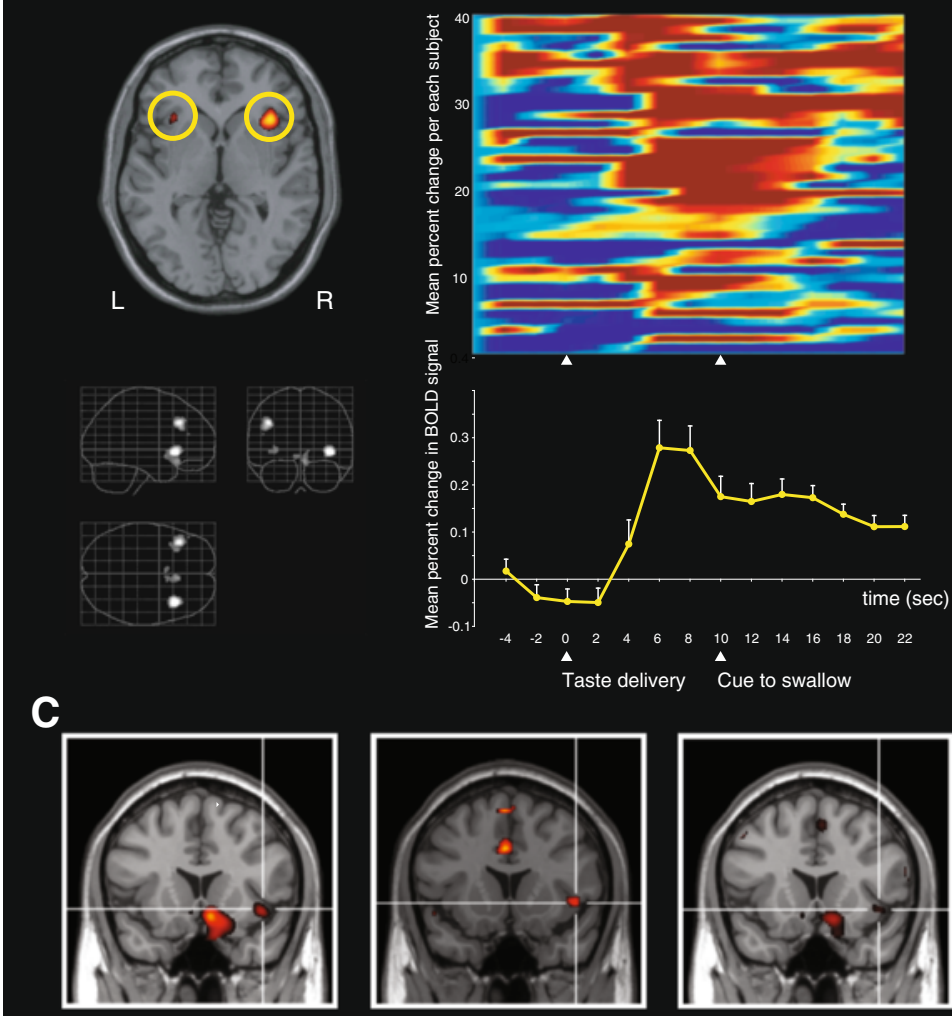

Orthonasal smell

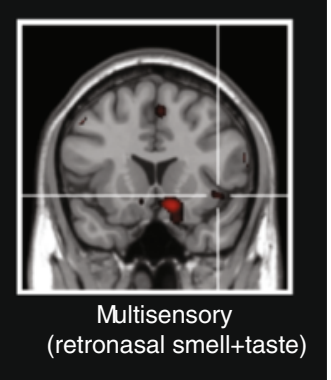

Figure 4 (See legend on next page.) 
(See figure on previous page.)

Figure 4 Motivation-independent representations of food in primary sensory cortices. Pure taste is the archetypical reinforcer associated with food. A) Consistent with findings in non-human primates, neuroimaging has located the primary human taste cortex in bilateral anterior insular/frontal opercular cortices (yellow circles) with peak MNI coordinates of $[x, y, z: 38,20,-4]$ and $[x, y, z:-32,22,0][53]$. B) This data is based on 40 datasets from four experiments using eight unimodal and six multimodal taste stimuli ranging from pleasant to unpleasant. Each small aliquot of $0.75 \mathrm{~mL}$ taste stimulus was delivered via polythene tubes to the mouth of the participant who was asked to move it around before being cued to swallow after typically $10 \mathrm{~s}$. To properly control and rinse out the effects of each stimulus, the taste stimulus was followed by a tasteless solution with the main ionic components of saliva. The time course of blood oxygen-level detection (BOLD) activity in right primary taste cortex is shown for all 40 subjects (top) and averaged across all (bottom) (for taste minus tasteless solution). C) Multisensory sensory integration was found in a region of the anterior insular cortex which responded to pure taste, orthonasal smell and flavour (retronasal smell and taste) [63].

exact coordinates of their putative primary taste cortex. It is thus difficult to trust this finding which is further undermined by visual inspection of the published figure, which clearly shows that the authors' purported primary taste cortex is located significantly posterior in the medial insular cortex, in contrast to the anterior insular primary taste region reported above and in all other careful neuroimaging taste studies.

\section{Learning-dependent multisensory representations}

Food-related decision-making depends on the integration of multisensory information about the food which includes information about temperature, viscosity, texture, fat contents, pungency and irritation mediated by a large variety of neural systems [25]. Neuroimaging this learning-dependent multisensory integration has found that the human orbitofrontal cortex integrates information from auditory [55], gustatory [51], olfactory [56], somatosensory [57] and visual [58] inputs, as well as information from the visceral sensory system [59]. The role of expectation and motivational control of appetite has also been investigated using restaurant menus which also found engagement of the orbitofrontal cortex [60] [61].

These human findings are consistent with neurophysiological recordings showing that the non-human primate orbitofrontal cortex receives input from all of the five senses [62]. These sensory inputs enter the orbitofrontal cortex primarily through its posterior parts and are integrated in more anterior areas [34]. The interaction between taste and smell revealed by neuroimaging is found in the orbitofrontal cortex and nearby agranular insula (Figure 4C) $[33,50,63]$.

\section{Reward representations of sensory stimuli}

Subsequent to establishing motivation-independent representations and multisensory representations of information about a food, affective valence is assigned, helping to guide prediction and decision-making. Again, pure taste serves as a good example with a neuroimaging study finding a dissociation between the brain regions responding to the intensity of the taste and its affective valence [64]. Another study found that subjective ratings of taste pleasantness correlated with activity in the medial orbitofrontal cortex (medial OFC) and in the anterior cingulate cortex [65] but, importantly, not with activity in the primary taste region, which was motivation-independent. Further evidence comes from experiments using orthonasal olfaction to show dissociable encoding of the intensity and pleasantness of olfactory stimuli, with the intensity encoded in the amygdala and nearby regions, and the pleasantness correlated with activity in the medial OFC (Figure 5A) and anterior cingulate cortex [66-68].

These reward-related findings in the medial OFC cohere with neuroimaging studies using other rewards. One study found a correlation between activity in the medial OFC with the amount of monetary wins and losses [69] (Figure 5B). Similarly, the subjective experience of methamphetamine over minutes was found to correlate with activity in the medial OFC [70] (Figure 5C). Even studies on the much shorter timescales of milliseconds have found activity in the medial OFC related to the reward of images of cute babies [71] (Figure 5D). These results point to the unity of reward-related activity in the pleasure system across many different rewards, which in turn suggest a system with a common currency of reward. Such a system would make it easier to decide and choose between different rewards.

\section{Representations of hedonic experience}

Finally, the evidence suggests that the subjective hedonic experience of food is encoded in activity in the pleasure system. In humans, the mid-anterior orbitofrontal cortex (mid-OFC) appears to be a key region as demonstrated by a selective-satiety neuroimaging study where activity in this region shows not only a selective decrease in the reward value to the food eaten to satiety (and not to the food not eaten) but also a correlation with pleasantness ratings (Figure 5E) [33]. This result indicates that the reward value of the taste, olfactory and somatosensory components of a food are represented in the orbitofrontal cortex and, therefore, that the subjective pleasantness of food might be represented in this region. Other studies have supported this finding, including an experiment investigating true taste synergism, where the intensity of a taste is dramatically enhanced by adding minute doses of another taste. The strong subjective enhancement of the pleasantness of umami taste that occurs when $0.005 \mathrm{M}$ inosine $5^{\prime}$-monophosphate is added to 

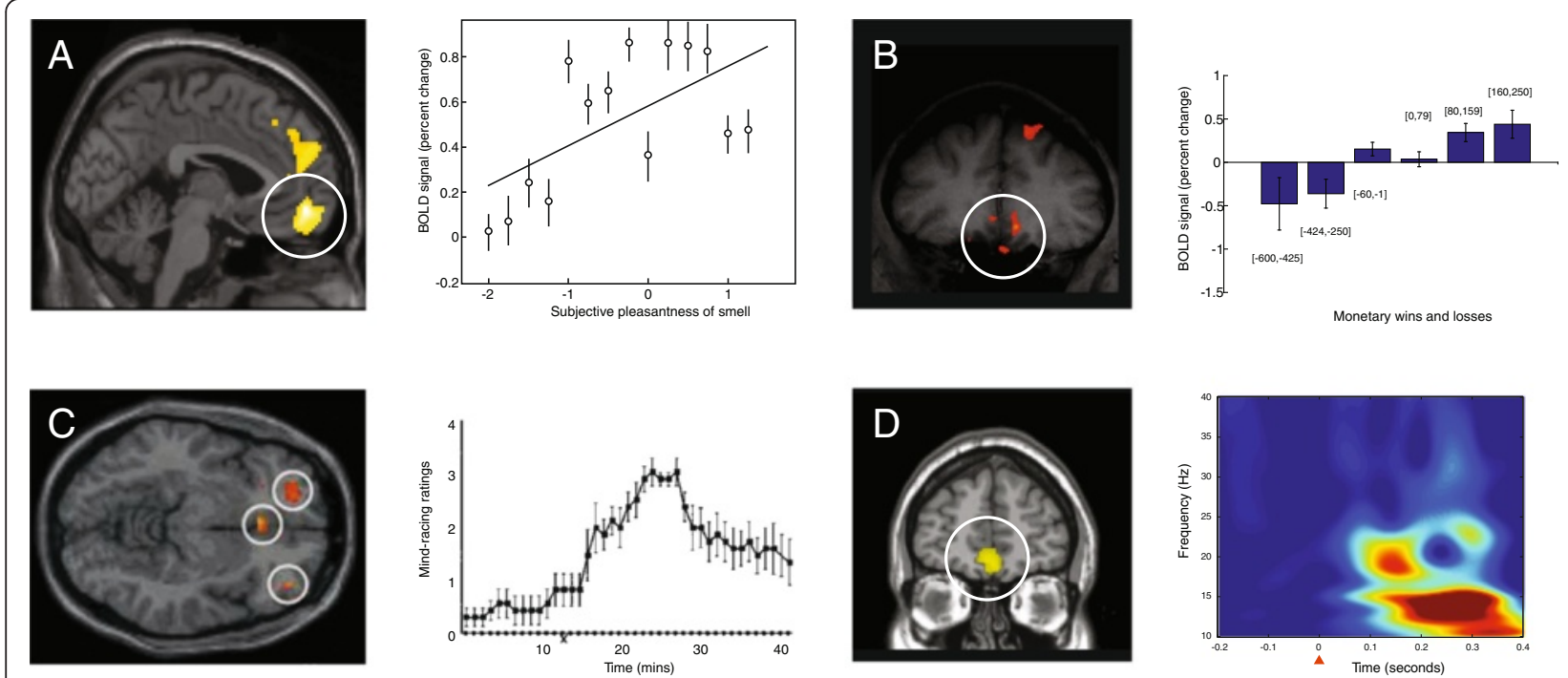

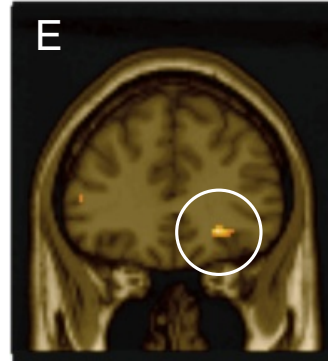

Selective satiety

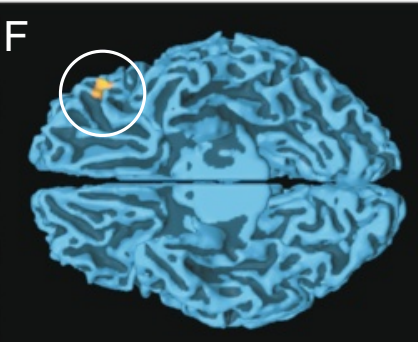

Pure taste synergy

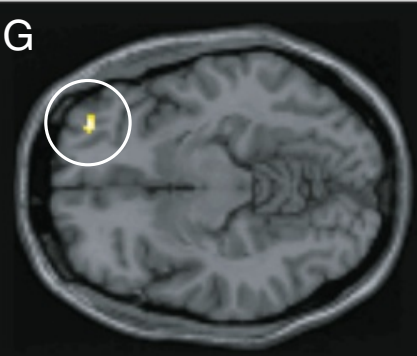

Multimodal enhancement

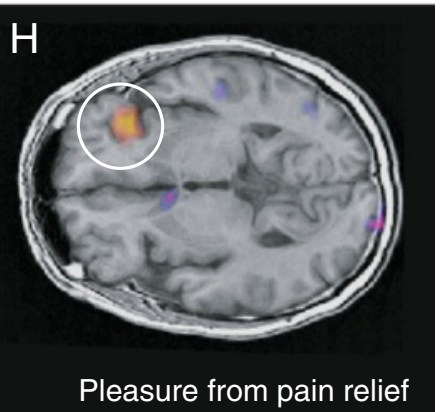

Figure $\mathbf{5}$ Reward in the human orbitofrontal cortex (OFC). Neuroimaging studies have revealed that the OFC is a heterogeneous brain region, where the different parts are engaged in different aspects of reward. Here, the focus is on the difference between activity in the medial OFC, which appears to monitor and evaluate the reward value (A-D), while the mid-anterior OFC (mid-OFC) contains activity encoding the subjective experience of pleasure (E-H). A) The activity in medial OFC is correlated with subjective ratings of pleasant and unpleasant smell [66]. B) Similarly, the activity in medial OFC is correlated with monetary wins and losses with no behavioural consequences [69]. C) Activity in the medial OFC is also tracking reward value over time, as shown in a neuroimaging study of the changing over minutes of pleasure of methamphetamine in drug-naïve participants [70]. D) The medial OFC also tracks the reward value of cute baby faces on faster timescales over milliseconds within 130 ms [71]. E) In contrast, activity in mid-OFC correlates with the subjective pleasure of food in a study of selective satiety [33]. F) Similarly, a study of supra-additive effects of pure taste combining the umami tastants monosodium glutamate and inosine monophosphate found subjective synergy effects in mid-OFC [72]. G) The synergy of supra-additive effects combining retronasal odour (strawberry) with pure sucrose taste solution was found in the mid-OFC [65]. H) Further, mid-OFC also became active when using deep brain stimulation in the PAG for the relief of severe chronic pain [73].

0.5 M monosodium glutamate (compared to both delivered separately) correlated with increased activity in mid-OFC (Figure 5 F) [72]. Similarly, investigations of the synergistic enhancement of a matched taste and retronasal smell found significant activity in the same midOFC region (Figure 5G) [63]. These food-related hedonic findings fit well with evidence coming from the study of other pleasures, including the finding of significant activity in mid-OFC in a study using magnetoencephalography (MEG) with deep brain stimulation to investigate the pleasurable relief from severe chronic pain (Figure 5H) [73].

\section{Conclusions}

As demonstrated poignantly by Babette's Feast, food is not only an important part of a balanced diet; it is also one of our main routes to pleasure. The novella opens many interesting question with regard to well-being and the good life and in particular shows that to allow oneself to be open to the possibility of pleasure of food is also allowing for the deep experiences of the multitude of pleasures. This is in sharp contrast to the denial of the pleasure of food leading to anhedonia, the lack of pleasure, which is a key constituent component of affective disorders. 
A

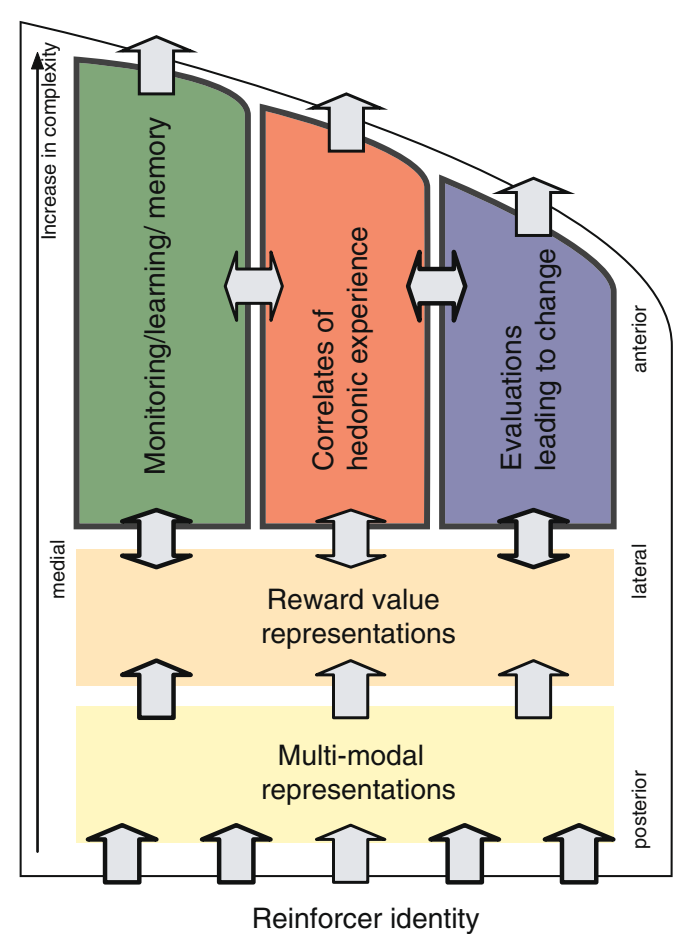

B
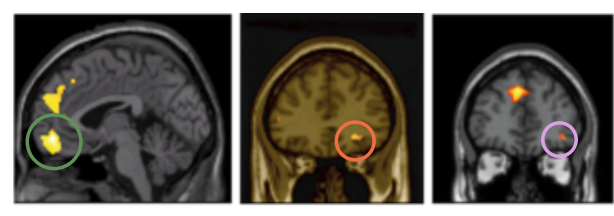

MOFC

IOFC

C

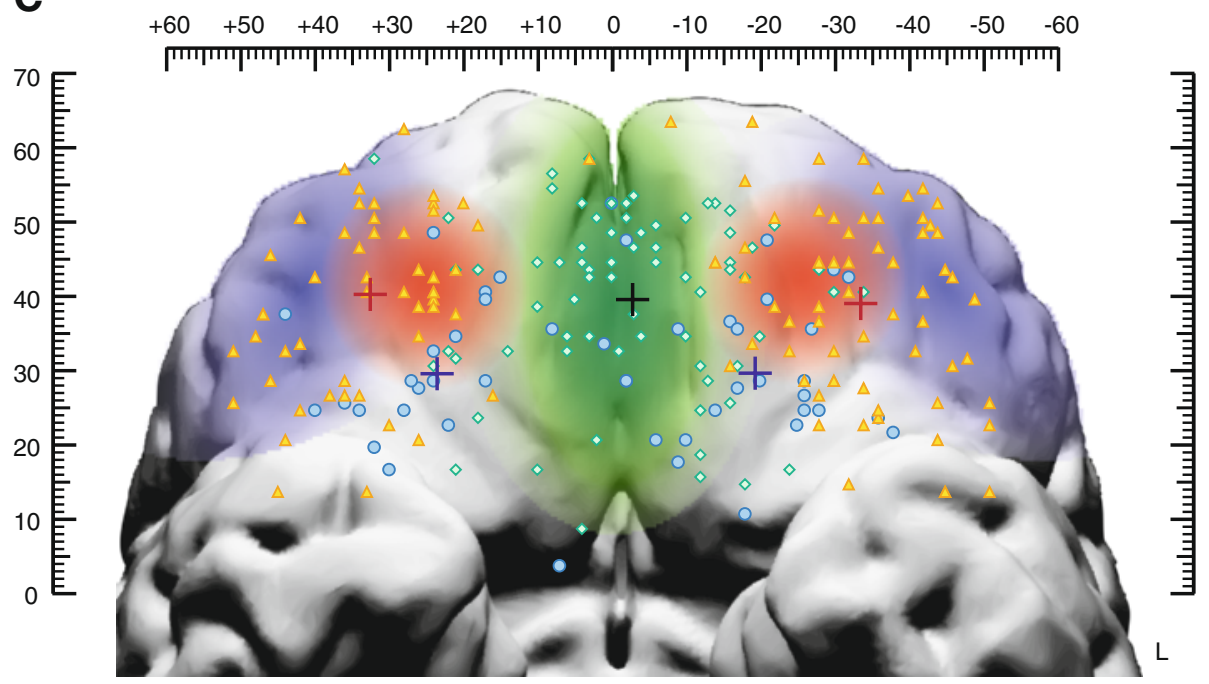

Figure 6 (See legend on next page.) 
(See figure on previous page.)

Figure 6 Model of information flow in the orbitofrontal cortex (OFC). The spatial heterogeneity of the human OFC has been revealed with neuroimaging. (A-C) The OFC is involved in most of the phases of the pleasure cycle, including evaluation, expectation, experience as well as decision-making and selection. Sensory information comes to the OFC where it is available for pattern association between primary (e.g. taste) and secondary (e.g. visual) reinforcers. Sensory information is combined in multisensory representations in the posterior OFC with processing increasing in complexity towards more anterior areas. The reward value of reinforcers is assigned in more anterior regions. This information is stored for valence monitoring/learning/memory (in medial OFC, green) and made available for subjective hedonic experience (in mid-OFC, orange) and used to influence subsequent behaviour (in lateral OFC with links to regions of anterior cingulate cortex, blue). The OFC participates in multiple modulatory brain-loops with other important structures in the pleasure system such as the nucleus accumbens, ventral pallidum, amygdala and hypothalamus, as well as modulation with autonomic input from the gut. [34]. B) Examples of monitoring reward value in medial OFC (green) was found in a study of orthonasal smell where the activity correlated with subjective ratings of pleasant and unpleasant smell [66]. Activity in mid-OFC (orange) correlates with the subjective pleasure of food in a study of selective-satiety [33]. In contrast, the activity in lateral OFC (shown in red) was found when changing behaviour in a rapid context-dependent reversal task of simple social interactions [84]. C) A large meta-analysis of neuroimaging studies confirmed the differential functional roles of these regions [34]. Future avenues of research include describing temporal unfolding of activity, similar to early involvement of the medial OFC ( $<130 \mathrm{~ms})$ in processing rewards such as cute babies and guide attentional resources [71].

The science of pleasure has made great strides in recent years [4], due not in small parts to using food as a pleasure-eliciting stimulus. As demonstrated in this review, the research has uncovered many of the fundamental brain mechanisms governing eating and pleasure in general. It has helped understand the brain's complex resource allocation problems with food competing with other rewards for time and resources. In particular, the brain must make important decisions of how best to balance exploration and exploitation to ensure survival. These decisions involve deciding when to pursue a reward, and whether to initiate, sustain and terminate the wanting, liking and learning processes involved in the different phases of the pleasure cycle (Figure 1). Eating is a complex process that involves many different factors over time as described in a multilevel model (Figure 2). The model demonstrates the cyclical changes in hunger levels related to the initiation and termination of meals, as they relate to signals from the brain, gut-brain, oral cavity, stomach and intestines, liver and metabolites and body mass.

Here, the focus has been on the computational principles for the multisensory processing of food information that initiates and terminates a meal, as well as the pleasure involved (Figure 3). Five main processing principles were discussed: 1) hunger and attentional processing; 2) motivation-independent processing of identity and intensity (Figure 4); 3) learning-dependent multisensory representations; 4) reward representations and 5) representations of hedonic experience. These principles are implemented within the orbitofrontal cortex that is a key, heterogeneous region in the pleasure system (Figures 5 and 6).

Furthermore, pleasure research has shown that food, sex and social interactions are fundamental to our survival and these basic stimuli take priority in resource allocation. It has also shown the unity of pleasure processing of different rewards, with food, sex, social and higher-order stimuli (such as music and money) in a unified pleasure system $[12,13,74-76,84]$.

Much remains to be done, but finally science has gained a toehold in understanding how pleasure can come to transform lives. Understanding the pleasure of food has played a major part in hedonia research and may even offer some insights into well-being. We have previously taken a lead from Aristotle's distinction between hedonia and eudaimonia (a life well-lived) to show how the study of pleasure may offer some insights into well-being [77].

Gastronomy offers the potential to expand on these findings and create exciting experiences and great pleasure. The rise of molecular gastronomy and gastrophysics have afforded chefs with unprecedented control over the production of novel flavours and textures of food [78,79]. These experiences are by their very nature multisensory and like all experiences highly dependent on expectation and prior experiences [80]. Using scientific tools and insights allows playful chefs to create unique and highly pleasurable dining experiences, e.g. using touch and sound as interesting extras in their gastronomical palette [81]. Yet, all foods are ultimately dependent on the state of the diner's brain and body [82], and the emergence of the neuroscience of the pleasure of gastronomy could help guide further progress $[11,83]$. Both the science and art of cooking stand to benefit much from future collaborations between scientists and chefs, especially in so far this research can help increase the pleasure of eating and well-being.

Babette's Feast shows how a sumptuous dinner can bring about much pleasure and transform lives. Babette uses all her money and skills on creating the once-in-alifetime dinner, yet at the end she tells the sisters: "A great artist, Mesdames, is never poor. We have something, Mesdames, of which other people know nothing". While it is true that creating great art takes skills and years of practice, it is also important to remember that every moment and every bite of food carries within it 
the possibility of pleasure. The brain is built for pleasure and it is through learning to appreciate the extraordinary in ordinary experiences, through pursuing the variety of pleasures rather than the relentless single-minded pursuit (hedonism) or denial of pleasure (asceticism) that a life well-lived can be constructed.

\section{Competing interests}

The author declares that he has no competing interests.

\section{Acknowledgements}

This research is supported by the TrygFonden Charitable Foundation.

Received: 19 December 2014 Accepted: 30 December 2014 Published online: 02 March 2015

\section{References}

1. Dinesen I. Babette's Feast. In: Anecdotes of destiny. London: Penguin; 1958

2. Kringelbach G. Forfatterne går til bords. Copenhagen: Erichsen; 1971.

3. Kringelbach ML. The orbitofrontal cortex: linking reward to hedonic experience. Nature Reviews Neuroscience. 2005;6:691-702.

4. Kringelbach ML, Berridge KC. Pleasures of the brain. New York: Oxford University Press; 2010.

5. Batterham RL, Ffytche DH, Rosenthal JM, Zelaya FO, Barker GJ, Withers DJ, Williams SC: PYY modulation of cortical and hypothalamic brain areas predicts feeding behaviour in humans. Nature 2007, 450:106-109.

6. Berthoud HR, Morrison C. The brain, appetite, and obesity. Annu Rev Psychol. 2008:59:55-92

7. Saper CB, Chou TC, Elmquist JK. The need to feed: homeostatic and hedonic control of eating. Neuron. 2002;36:199-211.

8. Woods SC. The control of food intake: behavioral versus molecular perspectives. Cell Metab. 2009;9:489-98.

9. Kohn M, Booth M. The worldwide epidemic of obesity in adolescents. Adolesc Med. 2003;14:1-9.

10. Kringelbach ML. Balancing consumption: brain insights from the cyclical nature of pleasure. In The interdisciplinary science of consumption. Edited by Preston S, Kringelbach ML, Knutson B. Cambridge, Mass.: MIT Press; 2014

11. Kringelbach ML. Food for thought: hedonic experience beyond homeostasis in the human brain. Neuroscience. 2004;126:807-19.

12. Kringelbach ML, Stein A, van Hartevelt TJ. The functional human neuroanatomy of food pleasure cycles. Physiol Behav. 2012;106:307-16.

13. Berridge KC, Kringelbach ML. Neuroscience of affect: brain mechanisms of pleasure and displeasure. Curr Opin Neurobiol. 2013;23:294-303.

14. Kringelbach ML, Berridge KC. A joyful mind. Scientific American. 2012;307:40-5

15. Lou HC, Joensson M, Kringelbach ML. Yoga lessons for consciousness research: a paralimbic network balancing brain resource allocation. Frontiers in Psychology. 2011;2:366.

16. Craig W. Appetites and aversions as constituents of instincts. Biological Bulletin of Woods Hole. 1918:34:91-107.

17. Sherrington CS. The integrative action of the nervous system. New York: C. Scribner's sons; 1906.

18. Robinson TE, Berridge KC. The neural basis of drug craving: an incentivesensitization theory of addiction. Brain Res Brain Res Rev. 1993;18:247-91.

19. Robinson TE, Berridge KC. Addiction. Annu Rev Psychol. 2003;54:25-53.

20. Berridge KC, Kringelbach ML. Affective neuroscience of pleasure: Reward in humans and animals. Psychopharmacology 2008;199:457-480.

21. Finlayson G, King N, Blundell JE. Liking vs. wanting food: importance for human appetite control and weight regulation. Neurosci Biobehav Rev. 2007;31:987-1002

22. Blundell JE, Burley VJ. Satiation, satiety and the action of fibre on food intake. Int J Obes. 1987;11 Suppl 1:9-25.

23. De Graaf C, De Jong LS, Lambers AC. Palatability affects satiation but not satiety. Physiol Behav. 1999:66:681-8.

24. De Araujo IE, Oliveira-Maia AJ, Sotnikova TD, Gainetdinov RR, Caron MG, Nicolelis MAL, et al. Food reward in the absence of taste receptor signaling. Neuron. 2008;57:930-41.

25. De Araujo IE, Simon SA. The gustatory cortex and multisensory integration. Int J Obes. 2009;33:S34-43.
26. Shepherd GM. Smell images and the flavour system in the human brain. Nature. 2006;444:316-21.

27. Van Hartevelt TJ, Kringelbach ML. The olfactory system. In The human nervous system 3rd Ed. Edited by Mai J, Paxinos G: San Diego: Academic Press; 2011: 1219-1238

28. Peciña S, Berridge KC. Hedonic hot spot in nucleus accumbens shell: where do mu-opioids cause increased hedonic impact of sweetness? J Neurosci. 2005;25:11777-86

29. Smith KS, Berridge KC. Opioid limbic circuit for reward: interaction between hedonic hotspots of nucleus accumbens and ventral pallidum. J Neurosci. 2007;27:1594-605

30. Cardinal RN, Parkinson JA, Hall J, Everitt BJ. Emotion and motivation: the role of the amygdala, ventral striatum, and prefrontal cortex. Neurosci Biobehav Rev. 2002:26:321-52.

31. Everitt BJ, Robbins TW. Neural systems of reinforcement for drug addiction: from actions to habits to compulsion. Nat Neurosci. 2005;8:1481-9.

32. Kringelbach ML. The hedonic brain: A functional neuroanatomy of human pleasure. In pleasures of the brain. Edited by Kringelbach ML, Berridge KC. Oxford, U.K.: Oxford University Press; 2010: 202-221

33. Kringelbach ML, O'Doherty J, Rolls ET, Andrews C. Activation of the human orbitofrontal cortex to a liquid food stimulus is correlated with its subjective pleasantness. Cerebral Cortex. 2003;13:1064-71.

34. Kringelbach ML, Rolls ET. The functional neuroanatomy of the human orbitofrontal cortex: evidence from neuroimaging and neuropsychology. Progress in Neurobiology. 2004;72:341-72.

35. Berridge KC. Food reward: brain substrates of wanting and liking. Neuroscience and Biobehavioral Reviews. 1996;20:1-25.

36. Watson KK, Shepherd SV, Platt ML. Neuroethology of pleasure. In pleasures of the brain. Edited by Kringelbach ML, Berridge KC. New York: Oxford University Press; 2010: 85-95

37. Amodio DM, Frith CD. Meeting of minds: the medial frontal cortex and social cognition. Nat Rev Neurosci. 2006;7:268-77.

38. Cabral J, Kringelbach ML, Deco G. Exploring the network dynamics underlying brain activity during rest. Prog Neurobiol. 2014;114:102-31.

39. Deco G, Kringelbach ML. Great expectations: Using Whole-Brain Computational Connectomics for Understanding Neuropsychiatric Disorders. Neuron 2014;84:892-905.

40. Kringelbach ML. Cortical systems involved in appetite and food consumption. In Appetite and body weight: integrative systems and the development of anti-obesity drugs. Edited by Cooper SJ, Kirkham TC. London: Elsevier; 2006: 5-26

41. Hetherington MM, Anderson AS, Norton GNM, Newson L. Situational effects on meal intake: a comparison of eating alone and eating with others. Physiology and Behavior. 2006;88:498-505.

42. de Graaf C, Kok FJ. Slow food, fast food and the control of food intake. Nat Rev Endocrinol. 2010;6:290-3.

43. Lenard NR, Berthoud HR. Central and peripheral regulation of food intake and physical activity: pathways and genes. Obesity (Silver Spring). 2008;16 Suppl 3:S11-22.

44. Shin AC, Zheng H, Berthoud HR. An expanded view of energy homeostasis: neural integration of metabolic, cognitive, and emotional drives to eat. Physiol Behav. 2009;97:572-80.

45. Zheng $H$, Lenard NR, Shin AC, Berthoud HR. Appetite control and energy balance regulation in the modern world: reward-driven brain overrides repletion signals. Int J Obes (Lond). 2009;33 Suppl 2:S8-13.

46. Grill HJ, Norgren R. The taste reactivity test. II. Mimetic responses to gustatory stimuli in chronic thalamic and chronic decerebrate rats. Brain Res. 1978;143:281-97.

47. Rozin P. Food preference. In: Smelser NJ, Baltes PB, editors. International Encyclopedia of the Social \& Behavioral Sciences. Amsterdam: Elsevier; 2001.

48. Veldhuizen MG, Rudenga KJ, Small D. The pleasure of taste flavor and food In Pleasures of the brain. Edited by Kringelbach ML, Berridge KC. Oxford, U.K.: Oxford University Press; 2010: 146-168

49. Kinomura S, Kawashima R, Yamada K, Ono S, Itoh M, Yoshioka S, et al. Functional anatomy of taste perception in the human brain studied with positron emission tomography. Brain-Res. 1994;659:263-6.

50. Small DM, Jones-Gotman M, Zatorre RJ, Petrides M, Evans AC. Flavor processing: more than the sum of its parts. Neuroreport. 1997:8:3913-7.

51. Small DM, Zald DH, Jones-Gotman M, Zatorre RJ, Pardo JV, Frey S, et al. Human cortical gustatory areas: a review of functional neuroimaging data. Neuroreport. 1999;10:7-14 
52. O'Doherty J, Rolls ET, Francis S, Bowtell R, McGlone F. Representation of pleasant and aversive taste in the human brain. J Neurophysiol. 2001;85:1315-21.

53. Kringelbach ML, de Araujo IE, Rolls ET. Taste-related activity in the human dorsolateral prefrontal cortex. Neuroimage. 2004;21:781-8.

54. Nitschke JB, Dixon GE, Sarinopoulos I, Short SJ, Cohen JD, Smith EE, et al. Altering expectancy dampens neural response to aversive taste in primary taste cortex. Nat Neurosci. 2006;9:435-42.

55. Frey $\mathrm{S}$, Kostopoulos $\mathrm{P}$, Petrides M. Orbitofrontal involvement in the processing of unpleasant auditory information. European Journal of Neuroscience. 2000;12:3709-12.

56. Zatorre RJ, Jones-Gotman M, Evans AC, Meyer E. Functional localization and lateralization of human olfactory cortex. Nature. 1992;360:339-40.

57. Rolls ET, O'Doherty J, Kringelbach ML, Francis S, Bowtell R, McGlone F. Representations of pleasant and painful touch in the human orbitofrontal and cingulate cortices. Cerebral Cortex. 2003;13:308-17.

58. Aharon I, Etcoff N, Ariely D, Chabris CF, O'Connor E, Breiter HC. Beautiful faces have variable reward value: fMRI and behavioral evidence. Neuron. 2001;32:537-51.

59. Critchley HD, Mathias CJ, Dolan RJ. Fear conditioning in humans: the influence of awareness and autonomic arousal on functional neuroanatomy. Neuron. 2002;33:653-63.

60. Hinton EC, Parkinson JA, Holland AJ, Arana FS, Roberts AC, Owen AM. Neural contributions to the motivational control of appetite in humans. Eur J Neurosci, vol. 20. pp. 1411-1418; 2004:1411-1418.

61. Arana FS, Parkinson JA, Hinton E, Holland AJ, Owen AM, Roberts AC. Dissociable contributions of the human amygdala and orbitofrontal cortex to incentive motivation and goal selection. J Neurosci. 2003;23:9632-8.

62. Rolls ET. The brain and emotion. Oxford: Oxford University Press; 1999.

63. De Araujo IET, Rolls ET, Kringelbach ML, McGlone F, Phillips N. Tasteolfactory convergence, and the representation of the pleasantness of flavour, in the human brain. European Journal of Neuroscience. 2003;18:2059-68.

64. Small DM, Gregory MD, Mak YE, Gitelman D, Mesulam MM, Parrish T. Dissociation of neural representation of intensity and affective valuation in human gustation. Neuron. 2003;39:701-11.

65. De Araujo IET, Kringelbach ML, Rolls ET, McGlone F. Human cortical responses to water in the mouth, and the effects of thirst. Journal of Neurophysiology. 2003;90:1865-76.

66. Rolls ET, Kringelbach ML, de Araujo IET. Different representations of pleasant and unpleasant odors in the human brain. European Journal of Neuroscience. 2003;18:695-703.

67. Anderson AK, Christoff K, Stappen I, Panitz D, Ghahremani DG, Glover G, et al. Dissociated neural representations of intensity and valence in human olfaction. Nature Neuroscience. 2003;6:196-202.

68. Gottfried JA, Deichmann R, Winston JS, Dolan RJ. Functional heterogeneity in human olfactory cortex: an event-related functional magnetic resonance imaging study. Journal of Neuroscience. 2002;22:10819-28.

69. O'Doherty J, Kringelbach ML, Rolls ET, Hornak J, Andrews C. Abstract reward and punishment representations in the human orbitofrontal cortex. Nature Neuroscience. 2001;4:95-102.

70. Völlm BA, de Araujo IET, Cowen PJ, Rolls ET, Kringelbach ML, Smith KA, et al. Methamphetamine activates reward circuitry in drug naïve human subjects. Neuropsychopharmacology. 2004;29:1715-22.

71. Kringelbach ML, Lehtonen A, Squire S, Harvey AG, Craske MG, Holliday IE, et al. A specific and rapid neural signature for parental instinct. PLOS ONE 2008, 3:e1664. doi:1610.1371/journal.pone.0001664.

72. De Araujo IET, Kringelbach ML, Rolls ET, Hobden P. The representation of umami taste in the human brain. Journal of Neurophysiology, vol. 90. pp. 313-319; 2003:313-319.

73. Kringelbach ML, Jenkinson N, Green AL, Owen SLF, Hansen PC, Cornelissen $\mathrm{PL}$, et al. Deep brain stimulation for chronic pain investigated with magnetoencephalography. Neuroreport. 2007;18:223-8.

74. Georgiadis JR, Kringelbach ML, Pfaus JG. Sex for fun: a synthesis of human and animal neurobiology. Nat Rev Urol. 2012;9:486-98.

75. Georgiadis JR, Kringelbach ML. The human sexual response cycle: Brain imaging evidence linking sex to other pleasures. Prog Neurobiol. 2012;98:49-81.

76. Gebauer L, Kringelbach ML, Vuust P. Ever-changing cycles of musical pleasure: the role of dopamine and anticipation. Psychomusicology, Music, Mind \& Brain. 2012;22:152-67.
77. Kringelbach ML, Berridge KC. Towards a functional neuroanatomy of pleasure and happiness. Trends in Cognitive Sciences. 2009;13:479-87.

78. McGee H. Q\&A: Harold McGee, the curious cook. Flavour. 2013;2:13.

79. Mouritsen $\mathrm{OG}$. The emerging science of gastrophysics and its application to the algal cuisine. Flavour. 2012;1:6.

80. Harrar V, Smith B, Deroy O, Spence C. Grape expectations: how the proportion of white grape in champagne affects the ratings of experts and social drinkers in a blind tasting. Flavour. 2013;3:25.

81. Spence C, Hobkinson C, Gallace A, Fiszman BP. A touch of gastronomy. Flavour. 2013;2:14.

82. Møller P. Gastrophysics in the brain and body. Flavour. 2013;2:8.

83. Shepherd GM. Neurogastronomy: how the brain creates flavor and why it matters. New York: Columbia University Press; 2011.

84. Kringelbach ML, Rolls ET. Neural correlates of rapid context-dependent reversal learning in a simple model of human social interaction. Neuroimage. 2003;20:1371-83

\section{Submit your next manuscript to BioMed Central and take full advantage of:}

- Convenient online submission

- Thorough peer review

- No space constraints or color figure charges

- Immediate publication on acceptance

- Inclusion in PubMed, CAS, Scopus and Google Scholar

- Research which is freely available for redistribution 